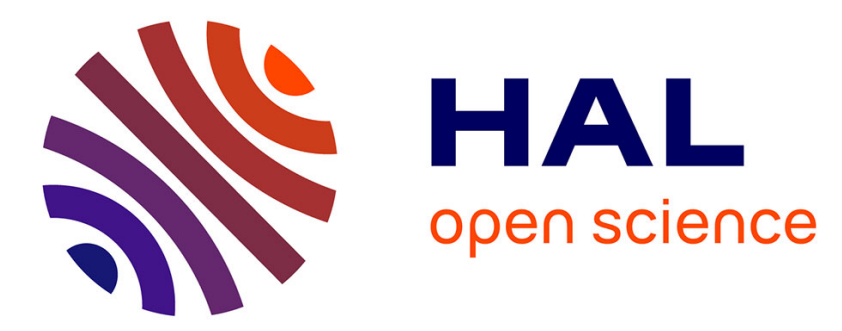

\title{
Single-domain antibodies: a versatile and rich source of binders for breast cancer diagnostic approaches.
} Klervi Even-Desrumeaux, Patrick Fourquet, Véronique Secq, Daniel Baty, Patrick Chames

\section{- To cite this version:}

Klervi Even-Desrumeaux, Patrick Fourquet, Véronique Secq, Daniel Baty, Patrick Chames. Singledomain antibodies: a versatile and rich source of binders for breast cancer diagnostic approaches.: Single-domain antibodies for breast cancer diagnosis. Molecular BioSystems, 2012, 8 (9), pp.23852394. 10.1039/c2mb25063b . inserm-00722930

\section{HAL Id: inserm-00722930 https://www.hal.inserm.fr/inserm-00722930}

Submitted on 6 Jul 2013

HAL is a multi-disciplinary open access archive for the deposit and dissemination of scientific research documents, whether they are published or not. The documents may come from teaching and research institutions in France or abroad, or from public or private research centers.
L'archive ouverte pluridisciplinaire HAL, est destinée au dépôt et à la diffusion de documents scientifiques de niveau recherche, publiés ou non, émanant des établissements d'enseignement et de recherche français ou étrangers, des laboratoires publics ou privés. 


\section{RSCPublishing $\begin{aligned} & \text { Molecular } \\ & \text { BioSystems }\end{aligned}$}

Single-domain antibodies: a versatile and rich source of binders for breast cancer diagnostic approaches

\begin{tabular}{|r|l|}
\hline Journal: & Molecular BioSystems \\
\hline Manuscript ID: & MB-ART-02-2012-025063.R3 \\
\hline Article Type: & Paper \\
\hline Date Submitted by the Author: & n/a \\
\hline Complete List of Authors: & $\begin{array}{l}\text { Even-Desrumeaux, Klervi; INSERM, CRCM } \\
\text { Fourquet, Patrick; INSERM, CIML } \\
\text { Secq, Veronique; INSERM, CRCM } \\
\text { Baty, Daniel; INSERM, CRCM } \\
\text { Chames, Patrick; INSERM, CRCM }\end{array}$ \\
\hline & \\
\hline
\end{tabular}

SCHOLARONE ${ }^{\text {m }}$

Manuscripts 


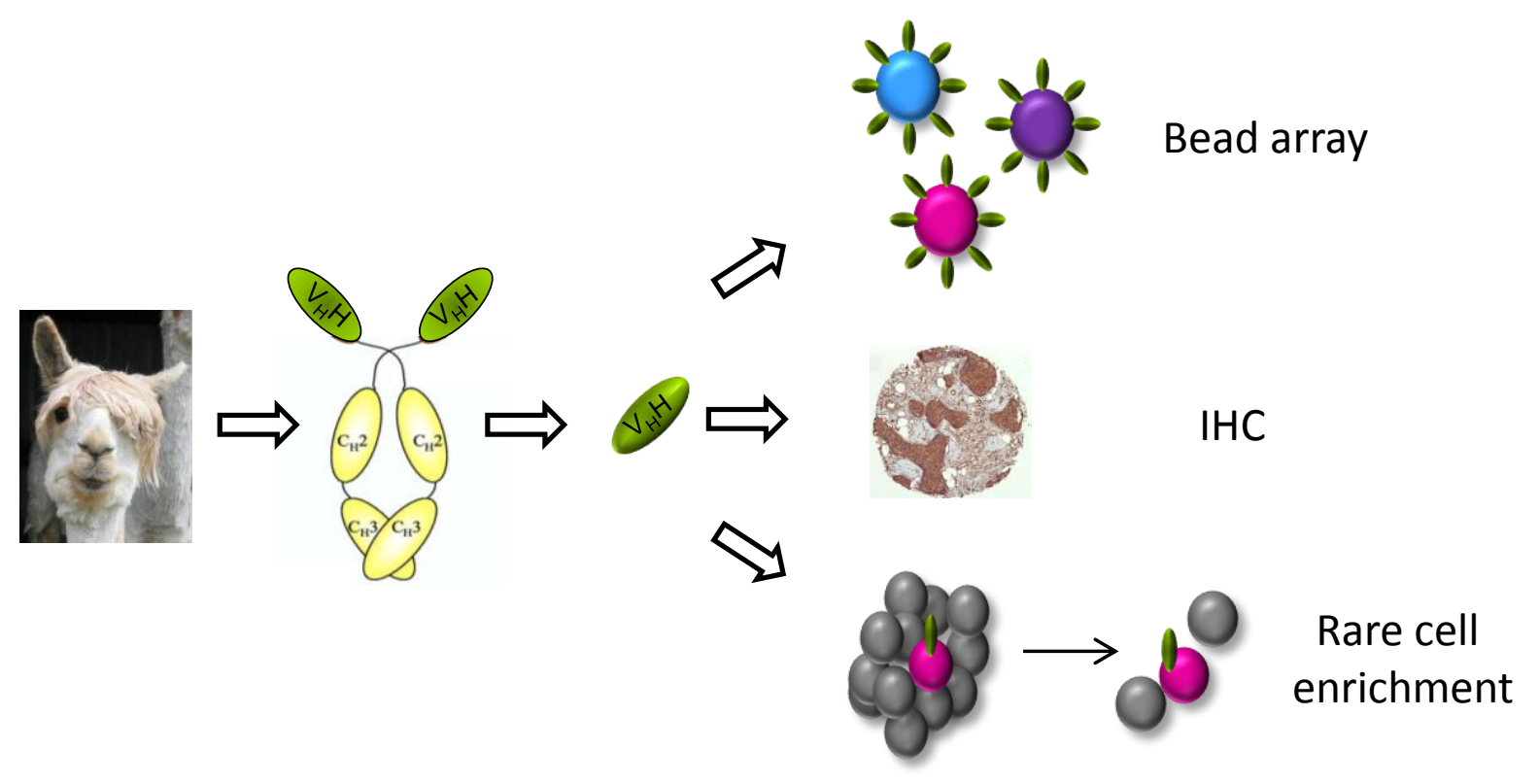




\section{Single-domain antibodies: a versatile and rich source of binders for breast cancer diagnostic approaches}

Klervi Even-Desrumeaux ${ }^{1,2,3,4}$, Patrick Fourquet ${ }^{5}$, Véronique Secq ${ }^{1,2,3,4}$, Daniel Baty ${ }^{1,2,3,4}$ and Patrick Chames ${ }^{1,2,3,4, *}$

${ }^{1}$ Inserm,U1068, CRCM, Marseille, F-13009, France

${ }^{2}$ Institut Paoli-Calmettes, Marseille, F-13009, France

${ }^{3}$ Aix-Marseille Univ, Marseille, F-13284, France

${ }^{4}$ CNRS, UMR7258, CRCM, Marseille, F-13009, France

${ }^{5}$ CIML, Marseille, F-13288, France

*Corresponding author: patrick.chames@inserm.fr Phone: +33 491828833 Fax +33 4 91826083

Running title: Single-domain antibodies for breast cancer diagnosis 


\begin{abstract}
Noninvasive early detection of breast cancer through the use of biomarkers is urgently needed since the risk of recurrence, morbidity, and mortality is closely related to disease stage at the time of primary surgery. A crucial issue in this approach is the availability of relevant markers and corresponding monoclonal antibodies suitable for the development of effective immunodiagnostic modalities. The identification of such markers from human pathological lesions and the isolation of specific antibodies using conventional approaches remain major challenges. Camelids produce functional antibodies devoid of light chains of which the single $\mathrm{N}$-terminal domain of the heavy chain is fully capable of antigen binding. When produced as an independent domain, these so-called single-domain antibody fragments (sdAbs) or nanobodies have several advantages for biotechnological applications owing to their unique properties of size $(13 \mathrm{kDa})$, stability, solubility, and expression yield.

In this work, we have generated phage display libraries from animal immunized with breast cancer biopsies. These libraries were used to isolate sdAbs against known and relevant antigens such as HER2, or several cancer-specific sdAbs against unknown targets. We describe the identification of one these targets, cytokeratin 19, using affinity purification in combination with mass spectrometry. Some of these sdAbs were used in several straightforward diagnostic applications such as immunohistochemistry analysis of tumor samples, multiplexed cytometric bead array analysis of crude samples, or an immune enrichment procedure of rare cells. Here, we demonstrate that phage display-based selection of single-domain antibodies is an efficient and high-throughput compatible approach to generate binders with excellent characteristics for the fast development of diagnostic and prognostic modalities.
\end{abstract}

\title{
Keywords
}

Single domain antibodies, cancer, diagnostic, biomarkers, beads array 


\section{Introduction}

Breast cancer is the most common cancer among women in Western countries. In France, 41,000 new cases are diagnosed each year and $25 \%$ of these women are below the age of 50. Breast cancer has a heterogeneous behavior and the frequency of metastasis in regional lymph nodules depends on tumor types ${ }^{1}$. Overall survival in breast cancer patients has been improved by the development of screening and treatment methods. While the 1980s saw a sharp rise in the number of new cases of breast cancer, that number now appears to have stabilized $^{1}$. The drop in the death rate from breast cancer is probably due to the fact that more women are having mammograms. When detected early, the chances for successful treatment of breast cancer are considerably improved.

However, the early diagnosis of breast cancer and an appropriate follow-up after surgical treatment are still major issues for the treatment of breast cancer. Mammographic imaging is the most effective approach to the diagnosis of breast cancer in women older than 50 years of age. Although new improvements are being made in the resolution of these imaging techniques, tumors smaller than $5 \mathrm{~mm}$ usually go undiagnosed ${ }^{2}$, and high-grade tumors can evolve very significantly during the interval between two check-up of regular mammography imaging, i.e. one to two years. For these reasons, new approaches are urgently needed to improve the early diagnosis of breast cancer and the overall and disease-free survival rates of patients.

Many studies have demonstrated significant variations of the expression level of several proteins during cancer development. These changes may cause measurable alterations of cancer cells and secretion of marker proteins into body fluids such as serum. Such tumor markers for breast cancer used in the clinic include cancer antigen 15-3 (CA 15-3), carcinoembyonic antigen $(\mathrm{CEA})^{3}$, and $\mathrm{HER}^{4}{ }^{4}$. Antibody-based techniques such as immunohistochemistry (IHC), enzyme-linked immunosorbent assay (ELISA) are widely used for diagnostic purposes of several antigens such as HER2, CEA, CA15-3 or hormonal receptors. For example, HER2 is a $185 \mathrm{kDa}$ protein composed of three domains: a cytoplasmic domain, a transmembrane domain, and an extracellular domain (ECD). The ECD of HER 2 can be cleaved from the surface of breast cancer cells by matrix metalloproteases and released into the serum. Increased levels of ECD $(\geq 15 \mathrm{ng} / \mathrm{mL})$ can be detected in approximately $15 \%$ to $30 \%$ of unselected presurgical breast cancer samples and in up to $45 \%$ of patients with metastatic breast cancer ${ }^{5}$. Measuring HER-2 is important for selecting optimal therapy and predicting prognosis in breast cancer patients. Current methods for evaluating 
HER-2 include the detection of shed antigen in the serum by enzyme-linked immunosorbent assay (ELISA) ${ }^{6}$, or the analysis of protein overexpression by IHC. IHC is now frequently used in the evaluation of many epithelial proliferations. Improved antigen retrieval techniques and a better understanding of biology have contributed to the broader utility of IHC for solving everyday diagnostic problems in breast pathology ${ }^{7}$.

In addition, new emerging antibody based approaches are now in development for breast cancer diagnosis. For example, microarray multiplex protein measurement of biomarker-based molecular diagnostic and prognostic cancer testing assays is destined to become a large growth segment of the immunodiagnostic industry. Protein microarrays are among the novel class of rapidly emerging proteomic technologies that might lead to efficient and specific diagnosis ${ }^{8}$. Microbead protein arrays use surface-coupled capture molecules and flow cytometry to simultaneously quantify several antigens. Multiplexing is achieved by either using different sized microbeads or color coding that is readable by a laser-induced fluorescent detection system ${ }^{9}$. This latter approach is suitable for the analysis of up to a hundred different bead-bound antibodies and/or proteins in a complex mixture. These assays can be directly compared to ELISA method ${ }^{10}$, but they require smaller volumes of sample material, and can be multiplexed. Thus bead array represents the method of choice for low density antibody array for clinical use such as diagnosis or prognosis ${ }^{11,12}$. This technique has the potential to generate non invasive and high throughput assay for screening and follow-up of large populations of women.

Another emerging and interesting diagnostic approach is the detection of circulating tumor cells (CTC) as an indicator of metastatic disease. Their detection is expected to provide a powerful tool for cancer prognosis, diagnosis of minimal residual disease, assessment of tumor sensitivity to anticancer drugs, and personalization of anticancer therapy ${ }^{13}$. CTC detection in blood samples may also be used to diagnose cancer and monitor a patient's response to therapy. Since CTCs are rare, comprising about one tumor cell among billions of normal blood cells in advanced cancer patients ${ }^{14}$, their detection and enumeration is a difficult task. Breast cancer circulating tumor cells are typically extracted from circulation through positive selection using epithelial cell-adhesion molecule (EpCAM), or HER2 as markers, leading to currently unknown biases when cells are undergoing epithelial-to-mesenchymal transition $^{14}$. To increase the specificity of this assay, one solution could be to use a large panel of antibodies targeting several membrane tumor antigens.

All this approaches are dependent on the availability of a variety of specific monoclonal antibodies (mAb). Unfortunately, it is not always easy to identify non-cross 
reactive mAbs against a large variety of markers. Moreover, their high production cost and their stability after immobilization are limiting factors for the development of some diagnostic assay ${ }^{15,16}$. The availability of large libraries of recombinant antibody fragments such as single chain $\mathrm{Fv}(\mathrm{scFv})$ or $\mathrm{Fab}$ is especially suited for these approaches but the stability and production yield of these fragments remain a limiting factor ${ }^{17}$. In 1993, Hamers-Casterman et $\mathrm{al}^{18}$ discovered that sera of camels, dromedaries and llamas contain a unique type of antibodies devoid of light chains. Camelids produce functional antibodies devoid of light chains (HCAbs). Single domain antibodies (sdAbs), corresponding to the variable domain of these antibodies have several advantages for biotechnological applications ${ }^{19,20}$ thanks to their unique properties including a small size $(13 \mathrm{kDa})$, a high stability even in the absence of disulfide bond formation ${ }^{21}$, a high solubility, and high expression yields ${ }^{22}$. Phage display technology has been extensively used to isolate tumor specific antibodies able to bind their cognate antigens in the cellular context ${ }^{23-29}$. It can be used to isolate binders against tumor specific markers ${ }^{30-35}$.

In this study, we have used phage display to isolate several relevant anti tumor markers sdAbs from immunized libraries. The straightforward use of these sdAbs for diagnostic approaches are also presented, including conventional assays such as ELISA or IHC, but also more innovative approaches such as multiplexed analysis of a complex sample by cytometric bead array (CBA) and the enrichment of rare cells in a complex sample by magnetic beads followed by flow cytometry characterization. 


\section{Results}

Selection of phage antibodies

Phage display was used to isolate antibodies against breast cancer specific targets. Various selection strategies were performed to obtain sdAbs against known and unknown targets.

\section{Selection of anti-HER2 sdAbs}

Although breast cancer is a very heterogeneous disease, $20-30 \%$ of tumors overexpress the human epidermal growth factor receptor 2 (HER2) ${ }^{36}$. SdAbs against this target are thus highly relevant for a diagnosis approach. To isolate such sdAbs, a llama was immunized with HER2expressing ovarian cancer cell line SKOv3 and a sdAb library was built and used to perform biopannings. The first round of selection was performed on purified recombinant HER2 ectodomain fused to a human Fc portion (HER2-Fc) followed by a second round on HER2positive SKBr3 cell line. After selection, 188 clones were screening and 92 clones were found positive by ELISA on HER2 positive cells (data not shown). Twenty clones were analyzed by sequencing, and all of them corresponded to a unique clone named $\mathrm{C} 7 \mathrm{~b}$. The fine specificity of this clone was confirmed by ELISA (Fig. 1A). SdAb C7b specifically bound to HER2-Fc fusion but not to an irrelevant Fc fusion, demonstrating its specificity for the HER2 ectodomain. Next, we used a flow cytometric based assay ${ }^{37}$ to determine the affinity of this $\mathrm{sdAb}$ on cells naturally overexpressing HER2, and compared to the affinity of a dimeric version of this sdAb (obtained by Fc fusion and called C7b-Fc) and to the FDA-approved anti-HER2 monoclonal antibody (Herceptin/trastuzumab) (Fig. 1B). The precise KD values were determined using the non-linear curve fitting program Prism (GraphPad) The affinity of the monovalent $\mathrm{sdAb}$ was $7 \mathrm{nM}, 11$-fold less than the bivalent herceptin affinity determined in parallel (600 pM). However, the measured affinity of C7b-Fc, a bivalent format of sdAb C7b directly comparable to Herceptin (bivalent $\mathrm{IgG}$ ), was $200 \mathrm{pM}$, i.e. threefold higher than the one of Herceptin (Fig. 1B). To confirm the affinity of sdAb C7b using an independent approach, a competitive ELISA using recombinant HER2-Fc antigen in solution was set up. The calculated $\mathrm{K}_{\mathrm{D}}$ of $5.3 \mathrm{nM}$ (Fig. 1C) was in close agreement with the flow cytometry data. Finally, we performed a competition analysis by flow cytometric assay between sdAb C7b and Herceptin (Fig. 1D). A large excess of Herceptin could not compete out sdAb C7b, demonstrating that these two molecules do not share their epitope. 
Selection of breast cancer-specific sdAbs of unknown specificity

To select binders against unknown breast cancer markers, llamas were immunized with breast cancer biopsy lysates. Phage libraries were built and panned using various approaches. Several selections were performed on different samples including a mixture of 9 breast cancer cell lines (BT474, SKBr3, HCC1954, MCF7, MDA-MB-231, T47D, HCC1806, BRCA-Mz01, HCC1937) and a mixture of 11 biopsy lysates (5801, 5772e, 5766, 5586, 5572i, 5592, $5011,5712,5713,5033,5627)$. After two rounds of panning, a primary screening was performed by phage-sdAb ELISA on maxisorp-adsorbed lysates corresponding to each selection. Positive clones were selected to perform a secondary screening step against 11 breast cancer biopsy lysates, a mixture of 9 breast cancer cell line lysates, one healthy breast cell line (HME1) as control of cancer specificity, and one patient PBMC (peripheral blood mononuclear cells) lysate as control of epithelial cell specificity. A final set of 20 unique clones were selected based on the diversity of their phage ELISA profile on breast cancer cell lines and biopsies and for their specificity of cancer sample. Fig $\mathbf{2 A}$ shows representative examples of this various patterns, including a clone binding to antigen differentially expressed in biopsies and cell lines, but negative on PBMC lysate (KE9), a clone showing a specificity restricted to breast cancer lysates and yielding no signal on biopsy lysates (KE36), or clones able to bind biopsy lysates but not cell line lysates (KE21 and KE15).

To establish the possibility to use sdAbs in diagnostic assay without the need of conventional mAbs, we tested the possibility to step up a sandwich ELISA using a couple of sdAbs targeting different epitopes of the same unknown cancer marker. To determine a relevant $\mathrm{sdAb}$ couple, series of sandwich ELISA were performed with all binders previously selected on various lysates. A couple of sdAbs leading to robust signals (KE23 for capture and KE32 for detection) was chosen as a proof of concept (data not show). This couple of sdAbs was used to determine the presence of their antigen in a mix of various breast cancer cell line and biopsy lysates by sandwich sdAb ELISA (Fig. 2B). The results suggest than the targeted antigen is differentially expressed in breast cancers. No signal was obtained using a lysate of healthy breast cell line (HME1) or human PBMC lysates, suggesting a specificity of these sdAbs for epithelial cancers. 
For most application, the identification of antigens recognized by these binders is of interest and permits the identification of monoclonal antibodies to be used in a sandwich approach for sensitive and quantitative determination of the antigen concentration in various disease samples. As a proof of concept, an approach was designed to elucidate the nature of the antigen recognized by $\mathrm{sdAb} \mathrm{KE}$. This sdAb was produced in the cytoplasm of E. coli in fusion with the avitag to allow an efficient and directed in vivo enzymatic biotinylation by BirA $^{38}$. The purified in vivo biotinylated $\mathrm{sdAb}$ was incubated with magnetic streptavidin beads before being incubated with one cell line lysate leading to strong signal by phage ELISA (T47D). A negative control was performed by using this lysate with an irrelevant $\mathrm{sdAb}$ anti-Nef ${ }^{39}$. A SDS-PAGE analysis of the immunoprecipitation revealed several strong specific bands in the $50 \mathrm{kDa}$ range (Fig. 3A). Mass spectrometry analysis of these bands identified the precipitated proteins as cytokeratin 19 (KRT19). The nature of KE9 antigen was confirmed by sandwich ELISA using KE9 as capture antibody, an anti-KRT19 mAb as detecting reagent and purified commercial KRT19 as antigen (Fig. 3B).

\section{Immunohistochemistry assays using single domain antibodies}

IHC is a common procedure performed that has acquired an increasingly prominent role in the diagnosis of breast pathology. To evaluate the efficiency of the selected single domain antibodies in IHC, we tested their reactivity on frozen embedded ductal breast cancer tissues (unrelated to biopsies used for immunization). As shown in Fig. 4, four sdAbs yielded intense stainings. Interestingly, various patterns could be obtained. SdAbs KE9, KE23, KE32 stained the cytoplasm of epithelial tumor cells whereas sdAb KE21 yielded a strong signal restricted to the nucleus of tumor cells. No staining was obtained in the absence of sdAb or using an irrelevant $\mathrm{sdAb}$. These results demonstrate that these sdAbs can be efficiently used to detect their antigen within this setting, independently of the cellular localization of their antigen.

\section{Multiplexed analysis using single domain antibodies immobilized on fluorescent beads}

This straightforward selection approach by phage display opens the possibility to rapidly select a variety of binders against various cancer samples and use the selected binders as binding unit to establish highly sensitive and quantitative diagnostic approaches. Therefore, we aimed at using the previously characterized binders to elaborate a multiplexed diagnostic assay for complex but precious samples such as biopsy lysates or patient serum. 
As a proof of concept, we decided to use previously isolated sdAbs against tumor markers HER2 and $\mathrm{CEA}^{25}$, together with the anti-KRT19 sdAb and the couple of sdAbs KE23/32 to build up a cytometric bead array assay. This approach uses the broad dynamic range of fluorescence detection offered by flow cytometry and antibody-coated beads to efficiently capture analytes. Each type of bead in the array is coded with a unique fluorescence intensity, and is functionalized with a different $\mathrm{sdAb}$, so that beads can be mixed and run simultaneously in a single tube. Four types of commercially available fluorescent beads were coated with streptavidin to immobilize in vivo biotinylated sdAbs on their surface in an orientated fashion $^{38}$. For this proof of concept, a complex sample was elaborated by mixing a patient serum containing a previously determined concentration of CEA, a purified recombinant HER2-Fc fusion, and the breast cancer biopsy lysate 5712 containing KRT19 and the unknown target. To evaluate the sensitivity of this approach, the precise concentration of KRT19 contained in this lysate was first established by traditional sandwich ELISA by comparison with a standard curve obtained with the purified antigen (data not show). All four antigens were simultaneously detected using the corresponding $\mathrm{mAb}$ for known targets or by phage-sdAb (KE32) for the unknown target. As seen in Fig. 5A, all antigens could be simultaneously detected with high sensitivity using a small amount $(50 \mu \mathrm{L})$ of complex sample.

\section{Magnetic enrichment of rare cells using single domain antibodies}

Streptavidin microbeads (Miltenyi Biotech) compatible with MACSQuant magnetic columns were used to evaluate the potential of biotinylated sdAbs as capture reagent for the enrichment of rare cells. As a proof of concept, anti-HER2 sdAb C7b was used to enrich breast cancer cells (SKBr3) from a large excess of human PBMC. A SKBr3:PBMC ratio of $3 \times 10^{3}: 6 \times 10^{6}$ was chosen to mimic the proportion of CTC in blood. The enrichment was monitored by following the percentage of HER2 positive cells using Herceptin. This simple procedure led to 276-fold enrichment of tumor cells compared to the initial ratio (Fig. 5B). Impressively, more than $97 \%$ of HER 2 positive cells could be retrieved despite the 2000 -fold initial excess of PBMC. 


\section{Discussion}

In this paper, we describe the selection of anti-tumor marker sdAbs and their straightforward use in several applications. Using the same library generated by immunization of llama with breast cancer biopsies, we selected sdAbs against known and relevant antigens such as HER2, or various sdAbs against unknown targets. Finally, some of these sdAbs were used to elaborate a sensitive and specific multiplexed assay on CBA to analyze a complex breast cancer representative sample. Other applications such as classical immunohistochemistry and an efficient and specific immune-enrichment of rare cells are also shown.

Surprisingly, a direct coating of cell lysates used for selections on maxisorp 96 well plates could be used to characterize the binding specificity of selected clones against a wide range of cell line and biopsy lysates. The high complexity of these lysates and the possible conformational changes of antigens due to the adsorption process might have prevented the generation of high signal for the monoclonal phage ELISA screening assay. We found that most selected phage clones could properly bind their antigens in these conditions. Bound phage were detected using an HRP-labeled monoclonal antibody directed toward p8, present at around 2800 copies per phage particle and allowing a considerable signal amplification. As such, phage ELISA on immobilized lysates represents a sensitive, robust, inexpensive and HT-compatible reverse phase array assay that can be exploited to test hundreds of binders against dozens of cell lysates. This approach could be used to generate antigenic profiles of various cancer related samples including cell line, biopsies or fluids such as serum samples.

We have shown the possibility to identify the antigen recognized by the selected phage-sdAbs. In a previous work, we had demonstrated the feasibility to produce active sdAbs in the cytoplasm of E. coli, fused to the avitag, a 15 aminoacid sequence which is biotinylated on a single lysine by $E$. coli enzyme BirA. This approach allows the efficient and inexpensive production of biotinylated sdAbs which can be directly immobilized on streptavidin coated surfaces such as plates or beads, in a near covalent and oriented fashion ${ }^{38}$. Here we have used this approach to immobilize sdAbs on magnetic streptavidin beads to immunoprecipitate the corresponding antigen. This approach was significantly more efficient than other ones, including the use of in vitro biotinylated sdAbs with streptavidin beads, his $6^{-}$ sdAbs with cobalt chelating beads, or direct covalent coupling of sdAb to epoxy beads (data not show). As proof of concept, the target of phage-sdAb KE9 was identified as cytokeratin 19 (KRT19). KRT19 is a relevant antigen for breast cancer analysis and is already used for 
immunohistochemistry analysis ${ }^{40}$, as tumor marker for serum analysis ${ }^{41,42}$ and for circulating tumor cells detection ${ }^{43}$. This result suggests that the proposed approach is capable of leading to the discovery of new relevant cancer related targets and biomarkers.

The in vivo biotinylation approach was also used to generate a sensitive multiplexed cytometry bead array. This assay can be directly compared to ELISA method ${ }^{10}$, but requires smaller volumes of sample material, and can be multiplexed. Thus bead array represents the method of choice for low density antibody array for clinical use such as diagnosis or prognosis $^{11,12}$. SdAbs have a tendency to bind cryptic epitopes normally inaccessible to conventional antibodies ${ }^{25}$. The anti-HER $2 \mathrm{sdAb}$ or the anti-KRT19 sdAb selected in this work seem to follow the same trend since they do not compete with trastuzumab or a commercial anti-KRT19 mAb, respectively. This characteristic facilitates the design of sandwich assays once the antigen is identified. Because we used in vivo biotinylation leading to the addition of a single biotin at the C-terminus of sdAbs, we could use fluorescently coded streptavidin beads that were coupled to a single sdAb before being mixed and incubated with the sample. This approach bypasses the need to covalently bind each chosen $\mathrm{sdAb}$ to a batch of fluorescent bead, and allows the HT-compatible generation of multiplexed bead arrays.

A necessary step in metastasis is the dissemination of malignant cells into the bloodstream, where cancer cells travel throughout the body as CTC in search of an opportunity to seed a secondary tumor. CTC detection represents a valuable diagnostic tool and can be used as liquid biopsy for prognostic and predictive purposes. There has been a push toward developing technologies to reliably detect CTC using a variety of molecular and immunocytochemical techniques. One of the numerous problems of CTC purification is the heterogeneous nature of CTC, and the difficulty to define appropriate specific antigens for their detection. The availability of several sdAbs targeting new anti-tumor makers might be helpful. Here, as proof of this concept, we describe a sensitive and powerful enrichment procedure of rare tumor cells using an anti-HER2 sdAb. Importantly, this system is highly flexible and only relies in the availability of relevant anti-tumor sdAbs. The use of two different sdAbs for targeting two markers for the capture and the detection is an easy way to enhance the specificity of this assay. The proposed approach to generate anti-tumor sdAbs being fully compatible with high throughput approaches; it becomes feasible to test various sdAb combinations to optimize this CTC assay.

Thus, the combination of phage display and single domain antibody technology appears as an attractive approach to rapidly generate a variety of binder whose characteristics 
are especially well adapted to the generation of inexpensive but powerful diagnostic tools for breast cancer diagnosis. 


\section{Materials and methods}

\section{Proteins}

sdAb CEA17 was previously described ${ }^{25}$.

Herceptin is a kind gift of Daniel Olive (CRCM, Marseille, France)

Plasmid pET-14b was used to produce in vivo enzymatically biotinylated sdAbs. All sdAbs produced in this vector carry a C-terminal his 6 -tag, preceded by the Avitag $^{\mathrm{TM}}$ (GLNDIFEAQKIEWHE). For generation of plasmids coding for sdAb-avitag ${ }^{\mathrm{TM}^{\mathrm{T}}-\mathrm{his}_{6}}$, see $^{38}$. To subclone sdAbs isolated by selection in pHEN1-PhoA-6HisGS plasmid ${ }^{44}$ in plasmids coding for sdAb-avitag ${ }^{\mathrm{TM}}$-his $_{6}{ }^{38}$, sdAb was first amplified from pHEN1-sdAb-myc-his 6 using primers pHENpETAvirev (CGTTCAGACCTGCGGCCGCTGAGGAGACAGTGACCTGG) and pHENpETAvifor (CtTtaAgaAgGagatataccatgGCCGagGtgCagctgGtG). Vector pET-sdAbaNef -avitag-his 6 was digested with NcoI and NotI and purified. Cloning by recombination was performed with InFusion $^{\mathrm{TM}}$ Advantage PCR Cloning Kits (clontech) as recommended by the manufacturer. All constructs were verified by nucleotide sequencing.

To subclone sdAbs isolated by selection (in pHEN1 plasmid) in plasmids coding for sdAb-Fc (Fc from human IgG1), sdAbs were first amplified from pHEN1-sdAb-myc-his 6 using primers 5HLsecVHH (GgttgcgtagctganaccggtgaggtgcagctgGtG) and 3VHHendH (CGgtgGgCatgtgtgagttttgtctgaggagacGgtgacctg). Vector pHLsec-sdAb-Fc was digested with AgeI and BstEII and purified. Cloning by recombination was performed using In-Fusion ${ }^{\mathrm{TM}}$ Advantage PCR Cloning Kits (clontech) as recommended by the manufacturer. All constructs were verified by nucleotide sequencing.

Serum sample, cells lines, biopsies

Patient sera were kindly provided by Pr. J.H.M. Cohen, (Université de Reims ChampagneArdenne, Reims). Concentration of soluble CEA in patient sera varied between 150 and 750 $\mathrm{ng} / \mathrm{ml}$ while CEA negative sera have a concentration of CEA lower than $5 \mathrm{ng} / \mathrm{ml}$.

MC38 are a kind gift of A. Pelegrin (INSERM U896, IRCM, Montpellier, France), MCF7, SKBr3, SKOv3 and T47D are a kind gift of Daniel Olive. MDA-MB-231 and HCC1937 are a kind gift of Marie Alix Poul (Laboratoire de Biologie et Pharmacologie Appliquée, Centre National de la Recherche Scientifique, UMR8113, Ecole Normale Supérieure de Cachan, 
France). BrCa-Mz-01, HCC1806, HCC1954 and BT474 are a kind gift of Jean Imbert (INSERM, U928, TAGC, Marseille, France). Cells lines MC38, SKOv3, MDA-MB-231, MCF7, T47D, HCC1937 were cultured in DMEM complemented with 10\% (v/v) fetal calf serum. Cells lines SKBr3, HCC1954, BrCaMz01, BT474 and HCC1806 were cultured in RPMI complemented with $10 \%(\mathrm{v} / \mathrm{v})$ fetal calf serum. HME1 cell line was purchased from ATCC and grown as recommended by the manufacturer. All cell lines were incubated at $37^{\circ} \mathrm{C}$ in a humidified atmosphere and with $5 \% \mathrm{CO}_{2}$. PBMC were isolated by ficoll gradient from the blood of healthy donors.

Informed consent was obtained from each patient prior to biopsy. Breast cancer biopsies references: (5801, 5772e, 5766, 5586, 5572i, 5592, 5011, 5712, 5713, 5033, 5627).

Biopsies or cells were lysed with a potter in lysis buffer : $150 \mathrm{mM} \mathrm{NaCl}, 1 \%$ Triton X-100, 50 $\mathrm{mM}$ Tris $\mathrm{HCl}$ pH8 with protease inhibitor cocktail (Complete, Roche). The lysate was centrifuged $10 \mathrm{~min}$ at $13000 \mathrm{~g}$ at $4^{\circ} \mathrm{C}$. Supernatant was the final cell lysate. Total protein concentration (average between $2-5 \mathrm{mg} / \mathrm{ml}$ ) was determined spectrophotometrically using a protein assay kit (Bio-Rad Laboratories, Hercules, CA, USA).

Production, purification and in vitro biotinylation of sdAbs

Production and purification procedures of in vivo biotinylated sdAbs was performed as described ${ }^{38}$.

In vitro biotinylation of protein was performed using Ez-link micro NHS-PEO4- biotinylation kit (Perbio science) following the recommendation of the manufacturer.

\section{Llama immunization and library construction}

Three young adult llamas (Lama glama) were immunized subcutaneously at days 1, 30, 60, 90 and 120 with breast cancer biopsy lysate $(4701,4952)$ or with healthy breast biopsy (one biopsy lysate per animal). One llama was immunized with 50 million of SKOv3 cells which strongly express HER2. VHH library construction was performed as described ${ }^{25,45}$. Briefly, genes coding for VHH were amplified by RT-PCR from the total RNA of peripheral blood mononuclear cells isolated by ficoll gradient, and cloned into phagemid pHEN1.

Selection of phage-sdAbs 
Phage-sdAb library was produced as described in ${ }^{25}$ using KM13 helper phage.

Different strategies of panning were performed. Phage selection were performed using antigen-coated magnetic epoxy beads (Dynabeads, invitrogen, following recommendations of the manufacturer), using 96-well maxisorp plate (Nunc) coated with antigen overnight at $4{ }^{\circ} \mathrm{C}$, or using $2 \times 10^{6}$ intact cells.. Beads, plate or cells were washed three times in PBS (using a magnetic particle concentrator for magnetic beads and centrifugation step for cells). PhagesdAb library $(1 \mathrm{ml})$ and beads, cells or plate were saturated in milk PBS $2 \%$. For selection including a depletion step, phage-sdAb libraries were incubated with depletion support with rotation during $2 \mathrm{~h}$ at room temperature or at $4^{\circ} \mathrm{C}$ for cells. Phage-sdAb libraries (depleted or not) were recovered and incubated with beads or plate with rotation during $2 \mathrm{~h}$ at room temperature or at $4^{\circ} \mathrm{C}$ for cells. Next, beads, cells or plate were washed ten times with $1 \mathrm{ml}$ of PBS $0,1 \%$ Tween (without tween for cells) and twice with PBS. Phage fixed on beads, cells or plates were eluted with tryspin solution (Sigma) at $1 \mathrm{mg} / \mathrm{ml}$ during $30 \mathrm{~min}$ at room temperature with rotation. Eluted phages were treated as described in ${ }^{25}$.

\section{ELISA assays}

\section{ELISA on epoxy beads}

HER2-Fc or human Fc ( R \& D systems) were immobilized on magnetic epoxy beads (Dynabeads, invitrogen) during $48 \mathrm{~h}$ at $4^{\circ} \mathrm{C}$ following recommendation of the manufacturer. For ELISA, $2 \mu \mathrm{l}$ of beads/well were used. Beads were blocked with 5\% milk-PBS (MPBS) for two hours at RT. Beads were washed and incubated for $1 \mathrm{~h}$ at RT with $50 \mu \mathrm{l}$ of $2 \%$ MPBS containing in vivo biotinylated sdAbs CEA17 or C7b at $10 \mu \mathrm{g} / \mathrm{ml}$ or HRP-conjugated anti-Fc $\mathrm{mAb}$ at $1 \mu \mathrm{g} / \mathrm{ml}$. After three washes with PBS, beads with sdAbs were incubated with HRPconjugated streptavidin (Jackson) $(1 \mu \mathrm{g} / \mathrm{ml})$ in 2\% MPBS for one hour at RT. After three washes in PBS, bound antibodies were detected using ABTS. Coloration was followed at 405 nm.

\section{Competitive ELISA on epoxy beads for affinity determination}

A fixed concentration of in vivo biotinylated sdAb C7b $(2 \mu \mathrm{g} / \mathrm{mL})$ was added to serial dilutions of soluble HER2-Fc antigen (fivefold dilutions starting from $1.25 \mu \mathrm{M}$ ). After $1 \mathrm{~h}$ of incubation at RT, the remaining free fraction of biotinylated $\mathrm{sdAb} \mathrm{C} 7 \mathrm{~b}$ was measured by incubating the mixture with $2 \mu 1$ of HER2-Fc immobilized beads per well (prepared as above) 
for $30 \mathrm{~min}$ at RT. After washing, bound sdAbs were detected as above. Dissociation constant was calculated using the non-linear curve fitting program Prism (GraphPad).

Phage-sdAb ELISA with lysate for screening and profiling

Monoclonal phage-sdAbs were produced as described in ${ }^{25}$. Phage-containing supernatants were tested for binding by ELISA.

Fifty $\mu \mathrm{l} /$ well of biopsy (5734, 5772ext, 5712, 5586, 5766, 5801, 5572int, 5592, 5627, 5011, 5033, 5713) or cell (BT474, SKBr3, HCC1954, MCF7, MDA-MB-231, T47D, HCC1806, BRCA-Mz-01, HCC1937, HME1, MC38, PBMC) lysates (200 $\mu \mathrm{g} / \mathrm{ml}$ of total proteins) were coated overnight at $4^{\circ} \mathrm{C}$ on maxisorp 96-well plate (Nunc). After three washes with PBS, plates were blocked with 5\% MPBS for two hours at RT. Plates were incubated for $1 \mathrm{~h}$ at RT with $25 \mu \mathrm{l} /$ well of phage-containing supernatants mixed to $25 \mu \mathrm{l} /$ well of $4 \%$ MPBS. After three washes with PBS Tween $0.1 \%$ and three washes in PBS, plates were incubated with HRP-conjugated anti-M13 mAb (Pharmacia) diluted 1/5000 for $1 \mathrm{~h}$ at RT. After three washes with PBS Tween $0.1 \%$ and three washes in PBS, bound secondary antibodies were detected using ABTS. Coloration was followed at $405 \mathrm{~nm}$.

\section{ELISA using a couple of sdAbs}

Streptavidin plates (Thermo scientific) were blocked with 5\% milk-PBS (MPBS) for two hours at RT. Fifty $\mu 1 /$ well of in vivo biotinylated sdAb at $10 \mu \mathrm{g} / \mathrm{ml}$ in $2 \%$ MPBS were incubated overnight at $4{ }^{\circ} \mathrm{C}$. Wells were washed and incubated for $1 \mathrm{~h}$ at RT with $50 \mu \mathrm{l}$ of $2 \%$ MPBS containing cell (BT474, SKBr3, HCC1954, MCF7, MDA-MB-231, T47D, HCC1806, BRCA-Mz-01, HCC1937, HME1, MC38, PBMC) or biopsy (5734, 5772ext, 5712, 5586, 5766, 5801, 5572int, 5592, 5627, 5011, 5033, 5713) lysates at $100 \mu \mathrm{g} / \mathrm{ml}$ of total proteins. After three washes with PBS tween $0.1 \%$ and three washes in PBS, plates were incubated $1 \mathrm{~h}$ at RT with $25 \mu \mathrm{l} /$ well of phage-containing supernatants mixed to $25 \mu \mathrm{l} /$ well of $4 \%$ MPBS. Following three washes with PBS tween $0.1 \%$ and three washes in PBS plates were incubated with HRP-conjugated anti-M13 mAb diluted 1/5000 for $1 \mathrm{~h}$ at RT. After three washes with PBS Tween $0.1 \%$ and three washes in PBS, bound secondary antibodies were detected using ABTS. Coloration was followed at $405 \mathrm{~nm}$.

Flow cytometry analysis 
Experiments were performed on ice with rocking in $1 \%$ BSA PBS. Typically, $2 \times 10^{5}$ cells resuspended in $50 \mu \mathrm{l}$ were distributed in 96-well microtiter plate, and incubated for $1 \mathrm{~h}$ with various concentrations of in vitro biotinylated antibodies. After washing, binders were detected with PE conjugated streptavidin (1:10) (Beckman Coulter). Fluorescence was measured using a MACSQuant (Miltenyi) and results were analyzed with the MACSQuant software. Negative (secondary antibody only) controls were carried out.

\section{Immunoprecipitation}

Cell lysates were depleted by incubation with magnetic streptavidin beads (Dynabeads, Invitrogen) for $2 \mathrm{~h}$ at RT. In the same time, in vivo biotinylated sdAbs were incubated with magnetic streptavidin beads during $1 \mathrm{~h}$ at RT ( $4 \mu \mathrm{g}$ of sdAbs for $100 \mu \mathrm{l}$ of beads for one immnoprecipitation). Beads were washed 3 times with PBS and incubated with depleted cell lysates during $2 \mathrm{~h}$ at RT under agitation. Beads with immune complexes were washed 5 times in lysis buffer and heated to $95^{\circ} \mathrm{C}$ for $5 \mathrm{~min}$ in $10 \mu 1$ of non-reducing protein loading buffer.

In-gel digestion and MALDI-TOF MS.

Protein spots excised from Coomassie blue (Imperial Protein stain, Pierce) stained gels were subjected to in-gel digestion with trypsin (Sequencing grade modified porcine trypsine; Promega, Madison, WI, USA) according to a modified protocol from Shevchenko et al. ${ }^{46}$. Tryptic peptides were then extracted from the gel, pooled and dried in a Speedvac evaporator. Mass analyses were performed on a MALDI-TOF-TOF Bruker Ultraflex spectrometer (Bruker Daltonics, Wissembourg, France) controlled by the Flexcontrol 3.0 package (Build 173.1). A list of contaminant ions was constituted from a blank sample (blank piece of gel treated and analysed exactly as a true sample) and substracted from sample peaklists before database search. The peptide mass lists were used to identify the protein using MASCOT software 2.2 (Matrix Science) available on site.

\section{Immunochemistry assay}

in vivo biotinylated nanobodies were tested in immunostaining on $5 \square \mu \mathrm{m}$ sections of frozenembedded cancer tissus. Endogenous peroxidase activity was blocked by incubation with 3\% $\mathrm{H}_{2} \mathrm{O}_{2}$. Slides were incubated for $1 \mathrm{~h}$ with $10 \mu \mathrm{g} / \mathrm{ml}$ of in vivo biotinylated nanobodies at RT. 
Detection was performed by incubations at RT for $30 \square \mathrm{min}$ with streptavidin peroxidase. Visualization was performed by DAB revelation (Dako) peroxidase reaction with haematoxylin as counterstain.

\section{CBA assay}

Three types of CBA Functional Bead system (BD Biosciences) were used for the assay.

The Functional Bead Conjugation Buffer Set was used for conjugation of streptavidin to beads following the recommendation of the manufacturer.

For multiplexed assay, $1.5 \times 10^{5}$ beads of each type were used per assay. The whole procedure was performed in the dark. Beads were coated with sdAbs individually and all types of beads were mixed for the rest of the procedure. Beads were blocked with 3\% BSA PBS for $2 \mathrm{~h}$ at RT. Beads were incubated with in vivo biotinylated sdAb (C7b, CEA17, KE9) at $10 \mu \mathrm{g} / \mathrm{ml}$ in $1 \%$ BSA PBS for $1 \mathrm{~h}$ at RT. After two washes with PBS, all bead types were mixed and incubated for $1 \mathrm{~h}$ at RT with serial dilutions of sample containing patient serum with CEA, recombinant HER2-Fc (R \& D systems) and a lysate of biopsy 5712. After two washes with PBS, beads were incubated for $1 \mathrm{~h}$ at RT with $2 \mu \mathrm{g} / \mathrm{ml}$ of anti-HER2 mAb (Santa-Cruz, sc74241), anti-CK19 mAb (Santa-Cruz, sc-53258) and anti-CEA mAb 35A7 (kind gift of A. Pelegrin, Montpellier). After two washes with PBS, beads were incubated for $1 \mathrm{~h}$ at RT with PE-conjugated goat anti-mouse mAb (Santa cruz) diluted 1/200. Fluorescence was measured using a MACSQuant (Miltenyi) and results were analyzed with the MACSQuant software. Negative controls (secondary antibody only) were carried out.

Rare cells enrichment assay

The enrichment procedure was performed using Streptavidin Microbeads (Miltenyi Biotech) following the recommendation of the manufacturer. Capture antibody was in vitro biotinylated sdAb C 7b at $10 \mu \mathrm{g} / \mathrm{ml}$. Detection antibody was Herceptin labeled with Alexa660 at $10 \mu \mathrm{g} / \mathrm{ml}$. Labeling was performed using Alexa Fluor ${ }^{\circledR} 660$ Protein Labeling Kit (Molecular Probes, Invitrogen) following the recommendation of the manufacturer. We used a ratio of 3000 SKBr3 cells mixed with 6000000 of human PBMC.

\section{Acknowledgements}


This work was supported by the ANR (Agence Nationale de Recherche) program 'Nanosciences and Nanotechnologies' under the grant ANR-07-PNANO-051-01 and by the ARC (Association pour la Recherche contre le Cancer). We would like to thank Matthieu Pophillat for excellent MS expertise.

\section{Competing interests}

The author(s) declare that they have no competing interests

\section{Authors' contributions}

KE-D performed most experiments, DB, KE-D and PC designed the experiments, KE-D and PC wrote the manuscript, VS provided biological samples, PF performed MS experiments. 


\section{References}

1. M. T. Tirona, R. Sehgal and O. Ballester, Cancer Invest, 2010, 28, 743-750.

2. S. N. Histed, M. L. Lindenberg, E. Mena, B. Turkbey, P. L. Choyke and K. A. Kurdziel, Nucl Med Commun, 2012.

3. E. Seregni, A. Coli and N. Mazzucca, Eur J Nucl Med Mol Imaging, 2004, 31 Suppl 1, S15-22.

4. R. A. Nunes and L. N. Harris, Clin Breast Cancer, 2002, 3, 125-135; discussion 136-127.

5. W. P. Carney, R. Neumann, A. Lipton, K. Leitzel, S. Ali and C. P. Price, Clin Breast Cancer, 2004, 5, 105-116.

6. $\quad$ M. van de Vijver, Oncology, 2002, 63 Suppl 1, 33-38.

7. M. F. Lerwill, Am J Surg Pathol, 2004, 28, 1076-1091.

8. M. Sanchez-Carbayo, Tumour Biol, 2010, 31, 103-112.

9. E. Morgan, R. Varro, H. Sepulveda, J. A. Ember, J. Apgar, J. Wilson, L. Lowe, R. Chen, L. Shivraj, A. Agadir, R. Campos, D. Ernst and A. Gaur, Clin Immunol, 2004, 110, 252-266.

10. M. F. Elshal and J. P. McCoy, Methods, 2006, 38, 317-323.

11. J. M. Schwenk, M. Gry, R. Rimini, M. Uhlen and P. Nilsson, J Proteome Res, 2008, 7, 31683179.

12. R. Rimini, J. M. Schwenk, M. Sundberg, R. Sjoberg, D. Klevebring, M. Gry, M. Uhlen and P. Nilsson, J Proteomics, 2009, 73, 252-266.

13. P. Paterlini-Brechot and N. L. Benali, Cancer Lett, 2007, 253, 180-204.

14. E. S. Lianidou and A. Markou, Clin Chem, 2011, 57, 1242-1255.

15. S. Dubel, O. Stoevesandt, M. J. Taussig and M. Hust, Trends Biotechnol, 2010, 28, 333-339.

16. T. Schirrmann, L. Al-Halabi, S. Dubel and M. Hust, Front Biosci, 2008, 13, 4576-4594.

17. A. Honegger, Handb Exp Pharmacol, 2008, 47-68.

18. C. Hamers-Casterman, T. Atarhouch, S. Muyldermans, G. Robinson, C. Hamers, E. B. Songa, N. Bendahman and R. Hamers, Nature, 1993, 363, 446-448.

19. L. Huang, S. Muyldermans and D. Saerens, Expert Rev Mol Diagn, 2010, 10, 777-785.

20. I. Vaneycken, M. D'Huyvetter, S. Hernot, J. De Vos, C. Xavier, N. Devoogdt, V. Caveliers and T. Lahoutte, Curr Opin Biotechnol, 2011, 22, 877-881.

21. D. Gueorguieva, S. Li, N. Walsh, A. Mukerji, J. Tanha and S. Pandey, FASEB J, 2006, 20, 26362638.

22. S. Muyldermans, J Biotechnol, 2001, 74, 277-302.

23. H. R. Hoogenboom, Nat Biotechnol, 2005, 23, 1105-1116.

24. U. B. Nielsen and J. D. Marks, Pharm Sci Technolo Today, 2000, 3, 282-291.

25. G. Behar, P. Chames, I. Teulon, A. Cornillon, F. Alshoukr, F. Roquet, M. Pugniere, J. L. Teillaud, A. Gruaz-Guyon, A. Pelegrin and D. Baty, FEBS J, 2009, 276, 3881-3893.

26. D. Kastelic, S. Frkovic-Grazio, D. Baty, G. Truan, R. Komel and D. Pompon, J Immunol Methods, 2009, 350, 54-62.

27. X. Cai and A. Garen, Proc Natl Acad Sci U S A, 1995, 92, 6537-6541.

28. R. C. Roovers, E. van der Linden, A. P. de Bruine, J. W. Arends and H. R. Hoogenboom, Eur J Cancer, 2001, 37, 542-549.

29. J. B. Ridgway, E. Ng, J. A. Kern, J. Lee, J. Brush, A. Goddard and P. Carter, Cancer Res, 1999, 59, 2718-2723.

30. C. Gao, S. Mao, F. Ronca, S. Zhuang, V. Quaranta, P. Wirsching and K. D. Janda, J Immunol Methods, 2003, 274, 185-197.

31. C. A. Geuijen, N. Bijl, R. C. Smit, F. Cox, M. Throsby, T. J. Visser, M. A. Jongeneelen, A. B. Bakker, A. M. Kruisbeek, J. Goudsmit and J. de Kruif, Eur J Cancer, 2005, 41, 178-187.

32. T. Heitner, A. Moor, J. L. Garrison, C. Marks, T. Hasan and J. D. Marks, J Immunol Methods, 2001, 248, 17-30.

33. B. Liu, F. Conrad, M. R. Cooperberg, D. B. Kirpotin and J. D. Marks, Cancer Res, 2004, 64, 704710. 
34. C. Marks and J. D. Marks, N Engl J Med, 1996, 335, 730-733.

35. C. Mazuet, D. Lerouge, M. A. Poul and N. Blin, Biochem Biophys Res Commun, 2006, 348, 550559.

36. Y. Yarden, Oncology, 2001, 61 Suppl 2, 1-13.

37. C. A. Benedict, A. J. MacKrell and W. F. Anderson, J Immunol Methods, 1997, 201, 223-231.

38. K. Even-Desrumeaux, D. Baty and P. Chames, Mol Biosyst, 2010, 6, 2241-2248.

39. J. Bouchet, S. E. Basmaciogullari, P. Chrobak, B. Stolp, N. Bouchard, O. T. Fackler, P. Chames, P. Jolicoeur, S. Benichou and D. Baty, Blood, 2011.

40. B. A. Gusterson, D. T. Ross, V. J. Heath and T. Stein, Breast Cancer Res, 2005, 7, 143-148.

41. C. Alix-Panabieres, J. P. Vendrell, M. Slijper, O. Pelle, E. Barbotte, G. Mercier, W. Jacot, M. Fabbro and K. Pantel, Breast Cancer Res, 2009, 11, R39.

42. V. Barak, H. Goike, K. W. Panaretakis and R. Einarsson, Clin Biochem, 2004, 37, 529-540.

43. L. Wang, Y. Wang, Y. Liu, M. Cheng, X. Wu and H. Wei, J Exp Clin Cancer Res, 2009, $28,57$.

44. N. Alvarez-Rueda, M. Z. Ladjemi, G. Behar, S. Corgnac, M. Pugniere, F. Roquet, C. BascoulMollevi, D. Baty, A. Pelegrin and I. Navarro-Teulon, Vaccine, 2009, 27, 4826-4833.

45. N. Alvarez-Rueda, G. Behar, V. Ferre, M. Pugniere, F. Roquet, L. Gastinel, C. Jacquot, J. Aubry, D. Baty, J. Barbet and S. Birkle, Mol Immunol, 2007, 44, 1680-1690.

46. A. Shevchenko, M. Wilm, O. Vorm and M. Mann, Anal Chem, 1996, 68, 850-858. 


\section{Figure legends}

Figure 1: sdAb C7b specificity and affinity. A) Epoxy beads were coated with HER2-Fc or Fc antigen, and incubated with anti-HER2 (C7b) or anti-CEA (CEA17) in vivo biotinylated sdAbs. Bound sdAbs were detected with HRP-conjugated streptavidin. HRP-conjugated anti$\mathrm{Fc}$ mAb were used as positive control of the presence of Fc fragments on beads. B) SKBr3 cells were incubated with serial dilutions of in vitro biotinylated $\operatorname{sdAb} \mathrm{C} 7 \mathrm{~b}(\bullet)$, Herceptin (ש) or C $7 b-F c(\Delta)$. Captured antibodies were detected by PE-conjugated streptavidin. Cells were analyzed by flow cytometry assay on MACSQuant. Error bars represent the standard deviation of MFI (mean fluorescence intensity) of experiments performed in triplicates. $\mathrm{K}_{\mathrm{D}}$ values were determining using non-linear fitting program Prism (GraphPad) C) $2 \mu \mathrm{g} / \mathrm{mL}$ of in vitro biotinylated $\mathrm{sdAb} \mathrm{C7b}$ was incubated with various concentrations of soluble HER2-Fc antigen. The free fraction of biotinylated $\mathrm{sdAb}$ was measured by incubation with bead coupled to HER2-Fc followed by washing and detection using streptavidin-HRP. Error bars represent the standard deviation of experiments performed in triplicates. D) SKBr3 cells were incubated with serial dilutions of Herceptin (1 to $0.000001 \mu \mathrm{M})$. In vitro biotinylated Herceptin at $0.001 \mu \mathrm{M}(\bullet)$ or sdAb C7b at $0.01 \mu \mathrm{M}(\mathbf{\bullet})$ were added. Captured antibodies were detected by PE-conjugated streptavidin. Cells were analyzed by flow cytometry assay on MACSQuant. Error bars represent the standard deviation of experiments performed in triplicates.

Figure 2: Phage-ELISA characterization of isolated sdAbs. A) Reverse phase ELISA. Maxisorp plate were coated with soluble protein lysate of biopsies (11 different biopsies), a mixture of breast cancer cell lines, named $\mathrm{BC}$ cell lines in the figure, and containing cell line lysates BT474, SKBr3, HCC1954, MCF7, MDA-MB-231, T47D, HCC1806, BRCA-Mz-01, HCC1937, human PBMC and healthy breast cell line HME1. Phage-sdAbs were added. Bound phage were detected with HRP-conjugated anti-M13 mAb. B) Sandwich sdAb ELISA. In vivo biotinylated sdAb KE23 was immobilized on streptavidin plates at $10 \mu \mathrm{g} / \mathrm{ml}$. Lysates of biopsies (same as in A), a mixture of breast cancer cell lines (BC cell lines, same as in A), human PBMC and healthy breast cell line HME1 were added. After washing, KE32 phage$\mathrm{sdAb}$ was added and bound phage were detected by HRP-conjugated anti-M13 mAb.

Figure 3: Targets identification. A) In vivo biotinylated KE9 sdAb or control sdAb (Cont.) were immobilized on streptavidin beads and used to perform immunoprecipitation using 
T47D cell line lysates. Immunoprecipitated proteins were analyzed under non-reducing conditions by SDS-PAGE. The low molecular weight bands correspond to streptavidin and immobilized sdAbs. B) Streptavidin plate were coated with in vivo biotinylated sdAb KE9. KRT19 antigen was added. After washing, anti-KRT19 mouse antibody was added and bound $\mathrm{mAb}$ were detected by HRP-conjugated anti-mouse antibody.

Figure 4: Immunohistochemistry assay. Frozen embedded ductal breast cancer tissue slides, corresponding to different samples, were incubated with in vivo biotinylated sdAbs. Bound sdAbs were detected by HRP-conjugated streptavidin. Original magnification, x20.

Figure 5: Breast cancer diagnosis assay with sdAbs. A) Multiplexed analysis of four breast cancer specific targets in a complex sample using a CBA assay. CBA beads were coated with streptavidin and incubated with in vivo biotinylated sdAb C7b, CEA17, KE9 or KE23. All beads were mixed and incubated with serial dilutions of serum containing CEA (starting concentration: $500 \mathrm{ng} / \mathrm{ml}$ ), HER2-Fc antigen (starting concentration: $10 \mu \mathrm{g} / \mathrm{ml}$ ), and biopsy 5712 lysate (starting concentrations: $100 \mu \mathrm{g} / \mathrm{ml}$ of total protein and $7 \mu \mathrm{g} / \mathrm{ml}$ of KRT19). Beads were incubated with phage-sdAb KE32, anti-CEA, anti-HER2 and anti-KRT19 mouse antibody. Anti-M13 mAb was added, followed by PE-conjugated goat-anti-mouse mAb. Beads were analyzed by flow cytometry assay on MACSQuant. Error bars represent the standard deviation of MFI (mean fluorescence intensity) of experiments performed in triplicates. B) Enrichment of rare cells. Enrichment of initial mixture of SKBr3 cells (3 000) in human PBMC (6 000 000) yielding an initial ratio of $0.05 \%$ of cancer cells. Cancer cells were enriched using in vitro biotinylated anti-HER2 sdAb C7b loaded on streptavidin microbeads, and detected with Alexa660 labeled Herceptin. Enrichment procedure was performed on the MACSQuant cytometer and analyzed by flow cytometry on the same device. 
Figure 1
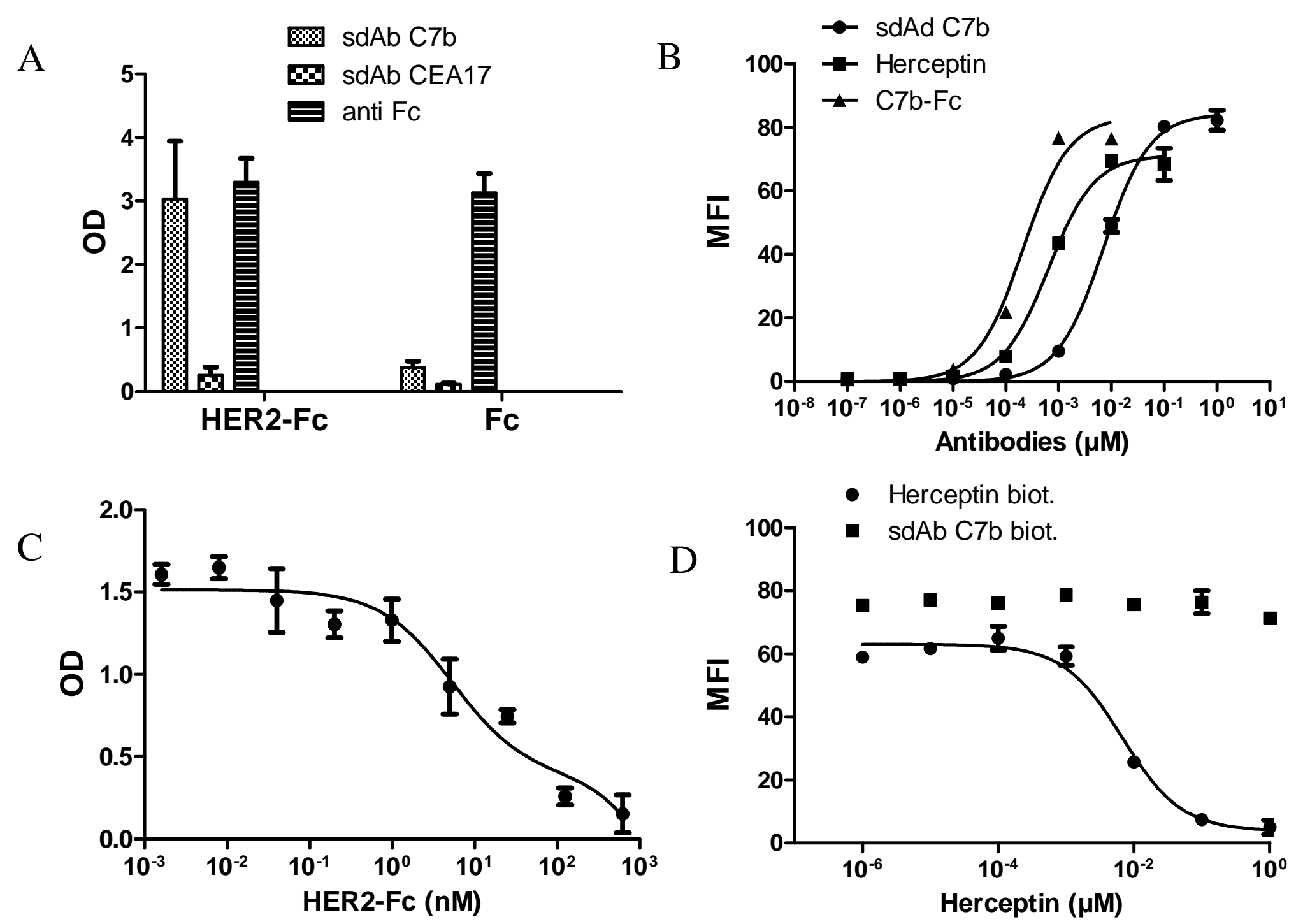
Figure 2

A

KE9

KE36

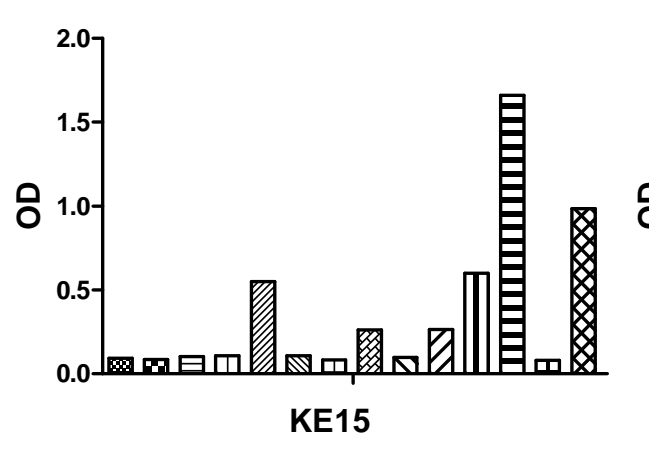

2.0
1.5
8
1.0
0.5
0.0

œ 5801

D $5572 e$

曰 5766
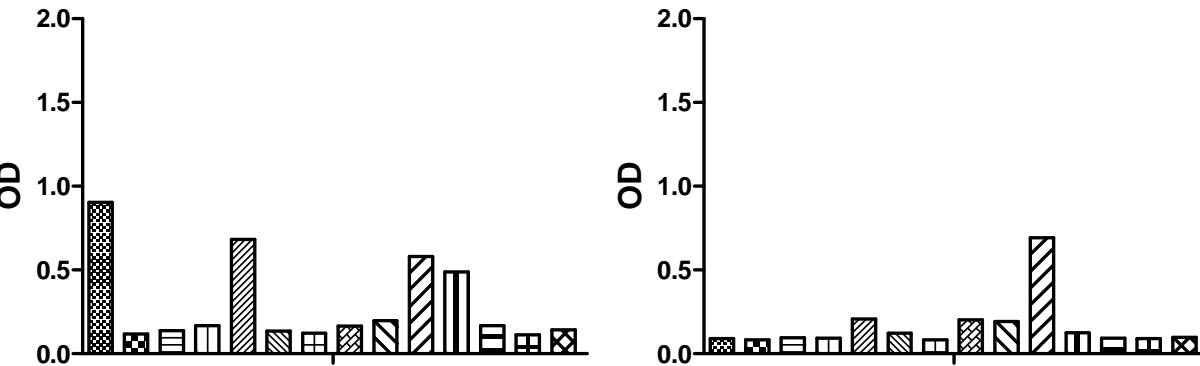

B

KE23/32

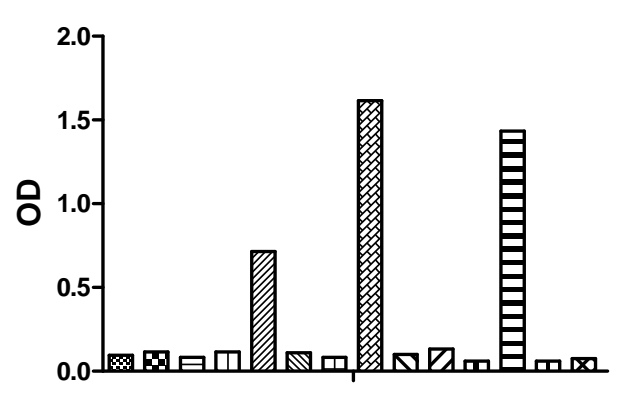

III 5572i

5592

世 5011

5712

자 5713

[D 5033

(II) 5627

BC cell lines

田 human PBMC

WME1 cells 
Figure 3

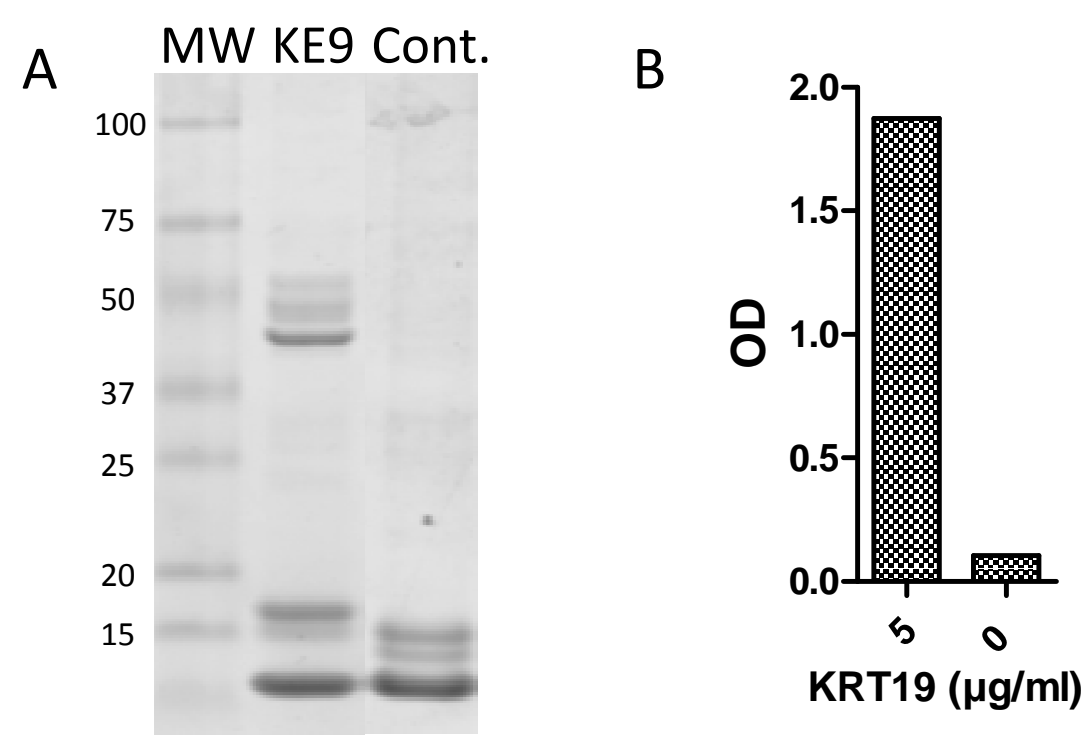


Figure 4
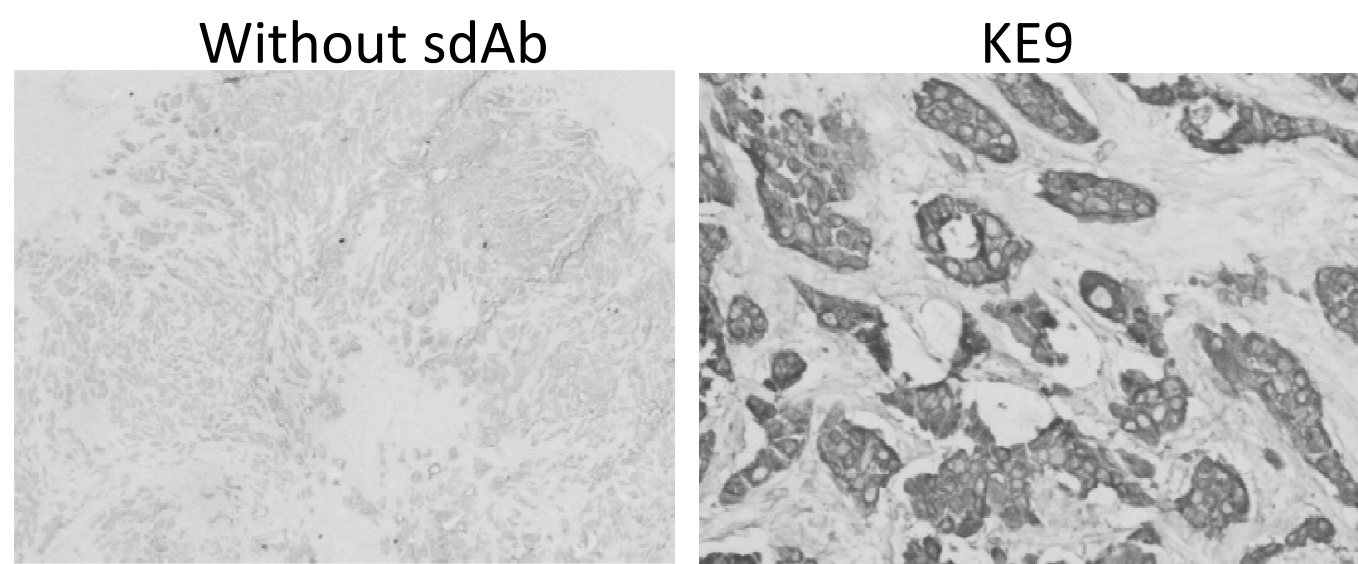

KE21

Irrelevant sdAb

KE23
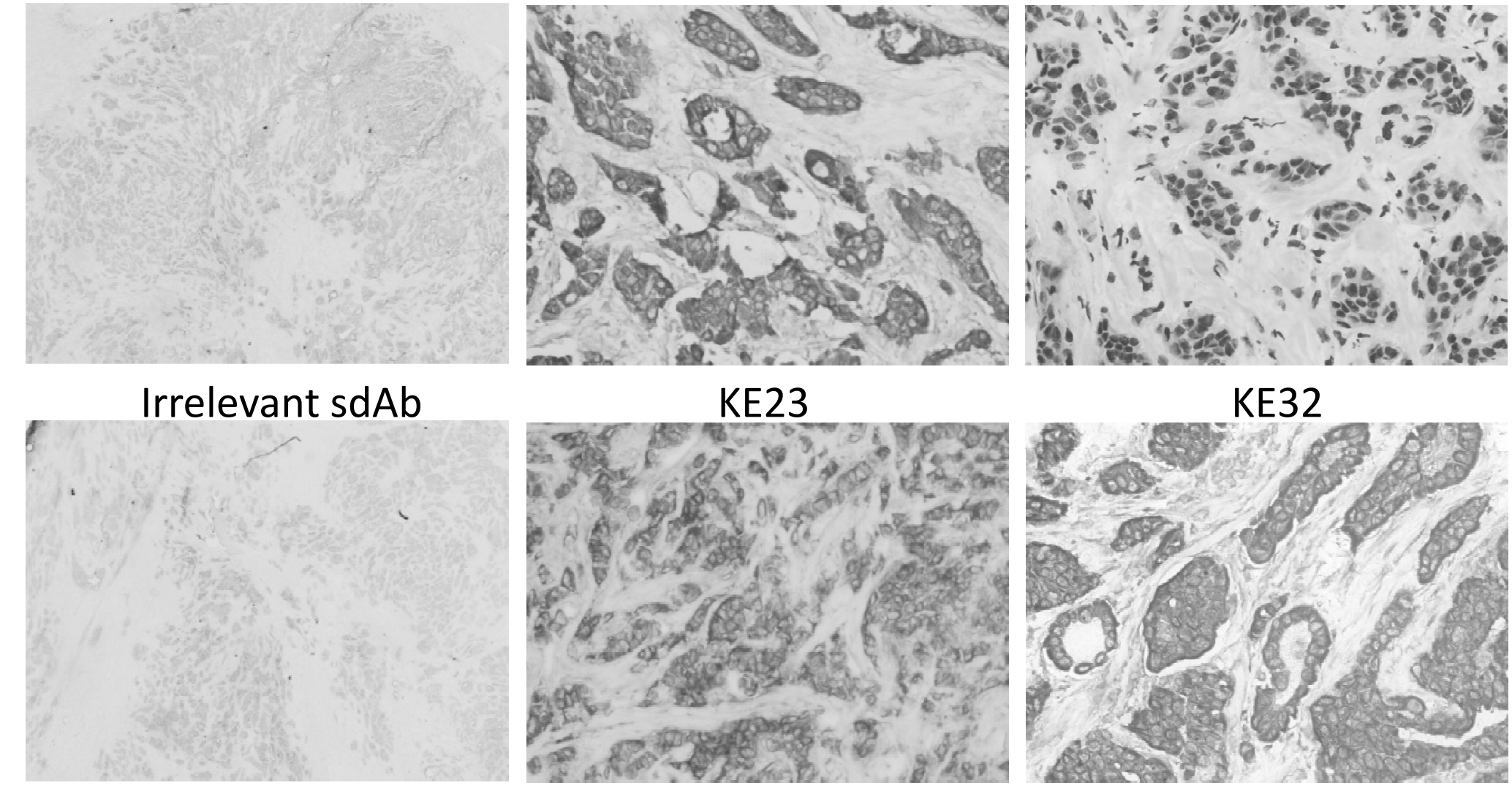

KE32

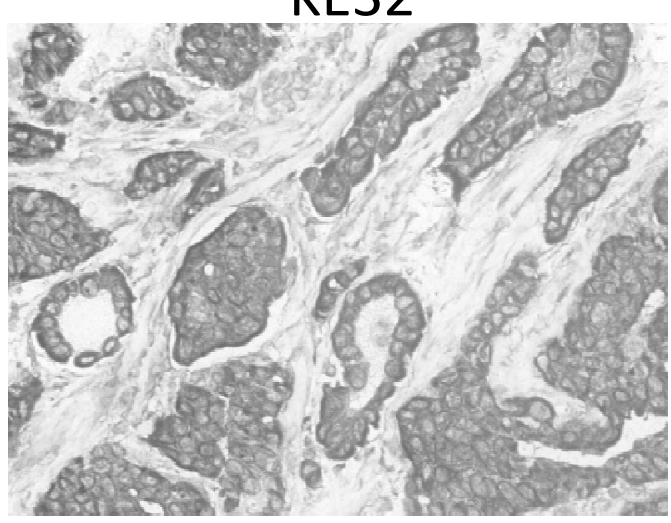




\section{Figure 5}

A

HER2
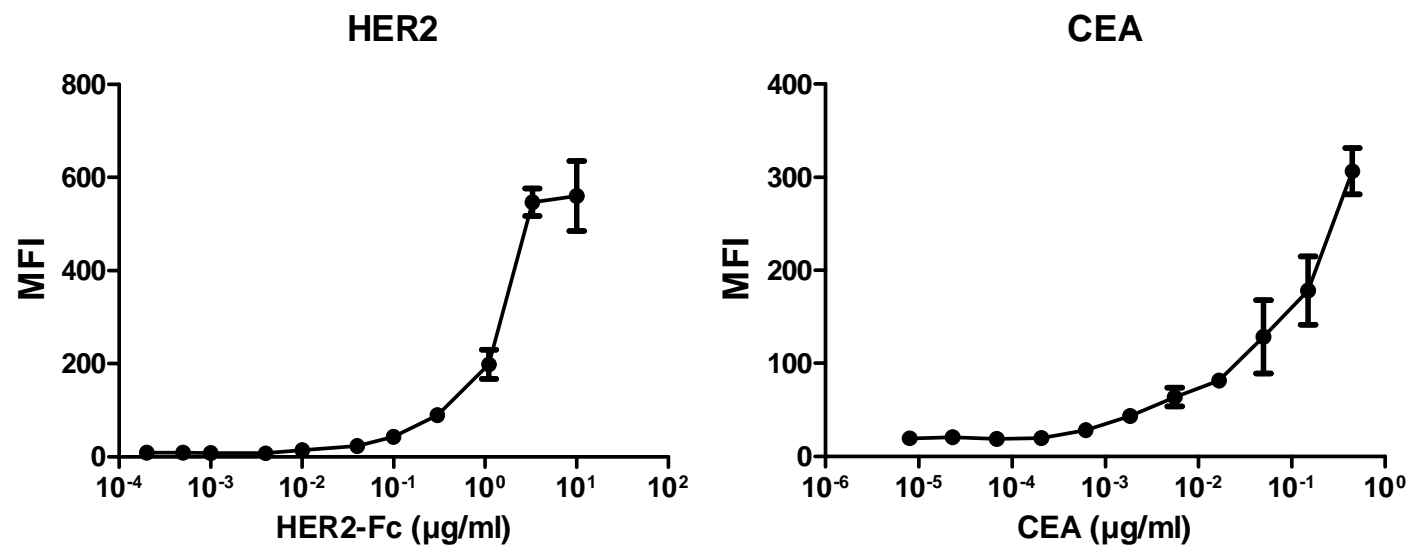

KRT19

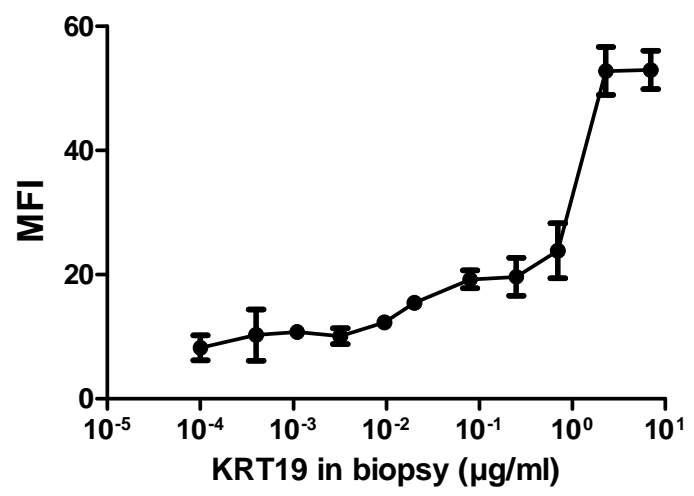

KE23/KE32

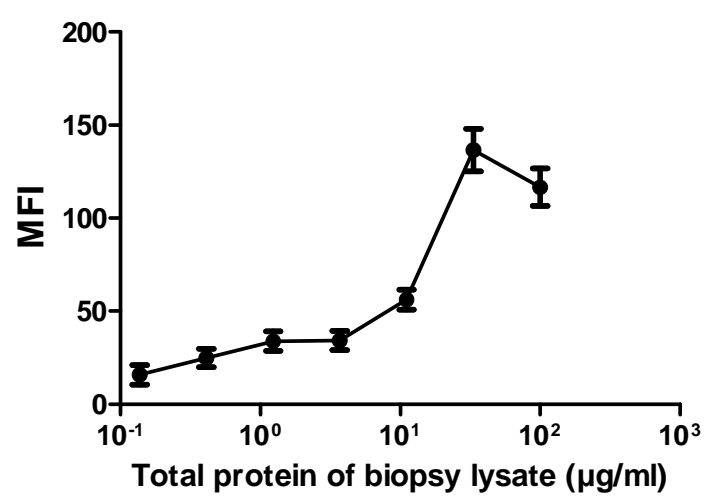

B

\begin{tabular}{|ccccccc|}
$\begin{array}{c}\text { Capture } \\
\text { sdAb }\end{array}$ & Total cells & $\begin{array}{c}\text { Total cells } \\
\text { (\% recovery) }\end{array}$ & $\begin{array}{c}\text { HER2+ } \\
\text { cells }\end{array}$ & $\begin{array}{c}\text { HER2+ cells } \\
\text { (\% recovery) }\end{array}$ & $\begin{array}{c}\text { HER2+ } \\
\text { cells (\% } \\
\text { final) }\end{array}$ & Enrichment \\
\hline $\mathrm{C7b}$ & 18650 & 0.31 & 2938 & 97.9 & 16.56 & 276 \\
\hline
\end{tabular}

